\title{
A RELAÇÃO PROFESSOR-ALUNO NO ENSINO DA ODONTOLOGIA NA UNIVERSIDADE FEDERAL DO ESPÍRITO SANTO
}

\author{
THE PROFESSOR-STUDENT RELATIONSHIP IN THE TEACHING OF DENTISTRY AT THE FEDERAL \\ UNIVERSITY OF ESPÍRITO SANTO
}

\author{
Aline Guio Cavaca ${ }^{1}$ \\ Carolina Dutra Degli Esposti ${ }^{2}$ \\ Edson Theodoro Santos-Neto ${ }^{3}$ \\ Maria José Gomes ${ }^{4}$
}

Resumo O objetivo do estudo foi analisar a relação professor-aluno no curso de Odontologia da Universidade Federal do Espírito Santo e discutir os possíveis reflexos dessa relação no processo ensino-aprendizagem. Trata-se de um estudo exploratório, de abordagem quantitativa, no qual foram aplicados questionários contendo perguntas fechadas e abertas a 130 alunos e 40 professores. Os resultados demonstram que $49 \%$ dos alunos e $45 \%$ dos professores consideram boa a relação professor-aluno. Quando questionados se já haviam sido repreendidos pelos professores na frente do paciente, $35 \%$ dos alunos responderam que nunca foram e $65 \%$ responderam já terem sido repreendidos pelo menos uma vez. A confiança no ensino foi trabalhada ao se questionar o professor se ele traria um parente para ser tratado nas clínicas do curso e $47 \%$ terem respondido positivamente, apontando a confiança no aluno, orientação dos professores e a qualidade do atendimento como norteadores de suas decisões. A relação professor-aluno é considerada boa para ambos, mas alguns fatores foram apontados como interferência negativa na qualidade do processo ensino-aprendizagem, como: a falta de acessibilidade e de interação pedagógica e social entre os atores, a arrogância e a intimidação por parte de professores e a falta de compreensão de limites por parte dos alunos.

Palavras-chave educação em saúde; ensino; aprendizagem; odontologia.
Abstract The aim of this study was to analyze the professor-student relationship at the Federal University of Espírito Santo's school of Dentistry and to discuss the possible impact this relationship has in the teachinglearning process. This is a quantitative exploratory study under which questionnaires containing both closed and open questions were applied to $130 \mathrm{stu}-$ dents and 40 professors. The results show that $49 \%$ of the students and $45 \%$ of the professors believe the professor-student relationship is good. When asked whether they had been reprimanded by the professors in front of a patient, $35 \%$ of students responded they had never been, while $65 \%$ said they had at least once. The trust in education was worked on by asking the professor if he or she would bring a relative to be treated at the school's clinics. In total, $47 \%$ responded positively, showing confidence in the students, in the professors' guidance, and in the quality of care as a guide for their decisions. The professor-student relationship is considered good for both, but a few factors were singled out as negative interferences in the quality of the teaching-learning process, such as the lack of accessibility and educational and social interaction among the players, the professors' arrogance and bullying, and the students' lack of understanding of their limits.

Keywords health education; teaching; learning; dentistry. 


\section{Introdução}

A temática sobre a formação profissional em saúde vem assumindo um papel de extrema importância desde a implantação do Sistema Único de Saúde (SUS) no Brasil. O novo perfil profissional exigido incita a discussão do modelo formador atual, o qual busca se adequar às demandas da sociedade. Nesse contexto, as instituições de ensino superior (IES) reavaliam seus modelos de formação e promovem iniciativas de mudanças curriculares.

O currículo representa o fundamento de um sistema de ensino. Dessa forma, para realizar mudanças na estrutura do sistema educacional, na organização da IES ou na escolha dos métodos a serem utilizados, devese reavaliá-lo. Nesse aspecto, as diretrizes curriculares nacionais (DCNs) nortearam esse movimento transformador e orientam a formação de profissionais com perfil generalista, humanista, crítico e reflexivo, tendo como base um conjunto de áreas de competência que, articuladas, produzem os resultados esperados (Brasil, 2002).

No que se referem ao campo disciplinar da Odontologia, alguns autores ressaltam que esta transita com dificuldade em meio às outras clínicas, isolandose em sua linguagem específica e não atuando sobre problemas sociais aos quais de fato se relaciona, o que traz implicações contraditórias diante do novo modelo assistencial do SUS (Kovaleski; Freitas; Botazzo, 2006; Botazzo, 2000).

O estudo de Esposti (2007) revelou a dificuldade que os cirurgiõesdentistas têm em trabalhar em equipe, no cenário da Estratégia Saúde da Família (ESF), como consequência de vários fatores, dentre eles a formação centrada em sua figura e a pressão sobre a produção técnica, individualizada, direcionada a eles ainda hoje por parte da gerência dos serviços de saúde.

O grande desafio é formar profissionais de saúde nas IES dotados de habilidades e competências para atuação no mercado de trabalho em seus diversos setores. Ceccim e Feuerwerker (2004) afirmam que as DCNs foram um importante passo para assinalar a necessidade de produzir mudanças no processo de formação, já que indicam um caminho, flexibilizam as regras para a organização de currículos e favorecem a construção de maiores compromissos da universidade com o SUS.

Para implementar estratégias educacionais inovadoras, tanto as instituições formadoras como os professores devem ter em mente que o ensino superior lida com adultos, ou seja, indivíduos com experiências individuais, que trazem consigo valores, interesses e dificuldades particulares, muito diferentes uns dos outros e sujeitos a mudanças (Noro et al., 2006). Em face dessa realidade, o professor deve atuar como mediador e facilitador do processo ensino-aprendizagem e não como única fonte de conhecimento, demonstrando a importância de uma boa interação docente-discente para o aprendizado do aluno. 
Masetto define o papel do professor nesse processo transformador:

(...) desenvolver a ação e a prática pedagógica do docente em aula: discussão do processo de aprendizagem, relação professor-aluno, reorganização de conteúdos, metodologias de aula mais apropriadas para que o aluno participasse e de fato aprendesse, revisão de um processo de avaliação em que continuasse um sistema de incentivo e motivação para a aprendizagem (Masetto, 2006, p. 31).

Bordenave e Pereira (2002) entendem que o ensino consiste na resposta planejada às exigências inerentes do processo de aprendizagem, sendo resultado da relação pessoal do professor com o aluno. Portanto, o professor, dependendo de suas atitudes, exerce efeito motivador ou pode levar ao desinteresse dos alunos, confirmando sua importância no desempenho acadêmico e no aprendizado do discente (Lazzarin; Nakama; Cordoni Júnior, 2007).

Noro et al. (2006), em um estudo realizado com professores e alunos de um curso de odontologia, visando comparar a visão deles sobre o papel do professor no aprendizado do aluno, perceberam que as características de um bom professor, apontadas pelos alunos, diziam respeito ao aspecto relacional $(50 \%)$ e cognitivo $(37,1 \%)$ em sua maioria. Já os professores caracterizam os melhores alunos de acordo com o aspecto motivacional (65\%), relacionado ao interesse intrínseco do aluno em aprender, definindo a transferência exclusiva ao aluno da sua responsabilidade pelo aprendizado.

Rozendo et al. (1999) definem que um processo educativo humanizado deve estar munido de práticas pedagógicas que não se preocupem apenas com conteúdo, técnicas de ensino ou avaliações, conceitos que frequentemente remetem ao binômio aprovação/reprovação. Muitas vezes, o descuido com o aspecto relacional pode conduzir a situações constrangedoras no desenvolvimento da aprendizagem do aluno, como no caso de repressões ao acadêmico na frente de um paciente, provocando sentimento de desconforto e desrespeito, o que pode levar à desmotivação e ao desinteresse pela disciplina.

$\mathrm{O}$ fato de um aluno, ou professor, confiar o tratamento de alguém de sua relação pessoal a um acadêmico de odontologia pode ser reflexo da confiança existente entre alunos e professores, desenvolvida no processo de ensino-aprendizagem. Apesar dessa possibilidade, em estudo realizado por Gonçalves e Verdi (2007) concluiu-se que existem problemas éticos e de abuso de autoridade por parte de professores e funcionários, que buscam privilégios no tratamento de pacientes com os quais têm estreita ligação.

Diante do exposto, este trabalho objetiva analisar a relação professoraluno no curso de Odontologia da Universidade Federal do Espírito Santo (Ufes) por meio da análise da qualidade dessa relação, da frequência de discussão entre professor-aluno e da repressão de alunos pelos docentes na frente dos pacientes, do estímulo dos professores e da confiança no trabalho 
realizado no curso. Além disso, pretende-se discutir os possíveis reflexos dessas questões no processo ensino-aprendizagem da odontologia.

\section{Metodologia}

Para alcançar os objetivos, delineou-se um estudo transversal descritivo exploratório, estruturado a partir de abordagem quantitativa.

Os sujeitos da pesquisa foram alunos e professores do curso de Odontologia da Ufes, entrevistados no período de julho a dezembro de 2007. Esse curso foi criado em 1950 e incorporado à Ufes em 1954. Atualmente, passa por uma mudança curricular, de acordo com as DCNs de 2002, passando a estruturar-se em dez períodos (a partir do semestre 2008/1), com duração de cinco anos. Possui aproximadamente 270 alunos matriculados/ano e 64 docentes.

$\mathrm{O}$ processo de amostragem considerou a estimativa da população de alunos cursando do $4^{\circ}$ ao $9^{\circ}$ período (180 indivíduos que possuem atividades clínicas), prevalência estimada de $50 \%$ para todas as categorias, precisão desejada de $6 \%$ e intervalo de confiança de $95 \%$, o que resultou no tamanho amostral de 130 alunos. Já o cálculo do tamanho amostral de professores considerou a quantidade aproximada de docentes (50) no curso de odontologia lotados nos departamentos com atividades clínicas e todos os demais critérios mencionados anteriormente, resultando num total de 41 indivíduos.

O instrumento de coleta de dados foi um questionário composto por cinco questões fechadas e três questões abertas que se reportavam às respostas das questões objetivas. As perguntas tinham como objetivo analisar a qualidade da relação professor-aluno, categorizada em níveis hierárquicos (ótima, boa, regular ou péssima). As perguntas que abordavam o tema 'discussão com o professor' ou 'repressão do aluno' foram classificadas de acordo com a frequência que ocorreram tais episódios. A questão do estímulo que o professor desperta no aluno e a confiança no trabalho realizado no curso foram categorizadas como positivas, negativas ou dependiam de outros fatores relatáveis.

As questões abertas intentavam fazer com que o participante da pesquisa justificasse a opção do nível hierárquico que escolhera na questão fechada, a fim de oferecer subsídios para o vislumbre de novas pesquisas que visarão explorar as especificidades da relação professor-aluno. Todas as respostas foram escritas e as categorias formadas a partir da repetição de núcleos comuns. Somaram-se os núcleos comuns e calcularam-se as frequências absolutas.

A aplicação dos questionários aos alunos e professores foi realizada por um único entrevistador. Foram distribuídos os questionários em sala de aula e recolhidos em seguida. Abordados individualmente, os professores receberam o questionário para serem respondidos e entregues posteriormente. 
Os dados foram processados e analisados no programa Microsoft Office Excel 2003, onde se construíram tabelas e gráficos de frequências relativas e absolutas das variáveis quantificadas.

O presente trabalho foi aprovado pelo Comitê de Ética em Pesquisa (CEP), da Universidade Federal do Espírito Santo (número de registro CEP 019/07), segundo a resolução 196/96 do Conselho Nacional de Saúde (Brasil, 1996). Todos os participantes da pesquisa assinaram o Termo de Consentimento Livre e Esclarecido, tendo garantido o sigilo da identificação pessoal.

\section{Resultados}

Os resultados encontrados sugerem que a relação professor-aluno no curso de Odontologia é considerada com grande frequência boa ou regular.

Conforme os Gráficos 1 e 2, a relação professor-aluno é considerada boa pela maioria dos professores (45\%) e alunos (49\%), mas destacam-se alguns pontos de fragilidade nessa relação, ao avaliarmos as considerações realizadas pelos indivíduos, que categorizaram a relação como regular $(30 \%$ dos professores e $44 \%$ dos alunos).

Gráfico 1

Distribuição percentual das variáveis relacionadas aos alunos do curso de Odontologia da Ufes, Vitória, Espírito Santo, 2007

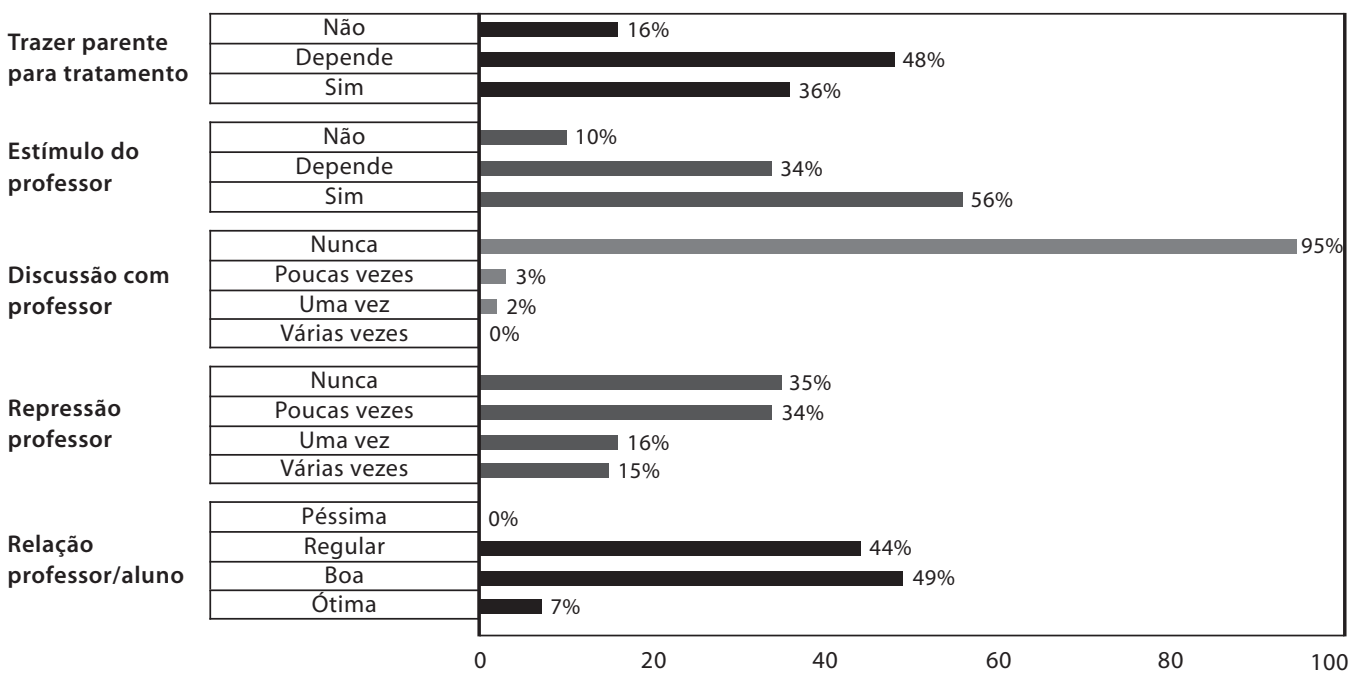

Fonte: Os autores. 
Gráfico 2

Distribuição percentual das variáveis relacionadas aos professores do curso de Odontologia da Ufes, Vitória, Espírito Santo, 2007

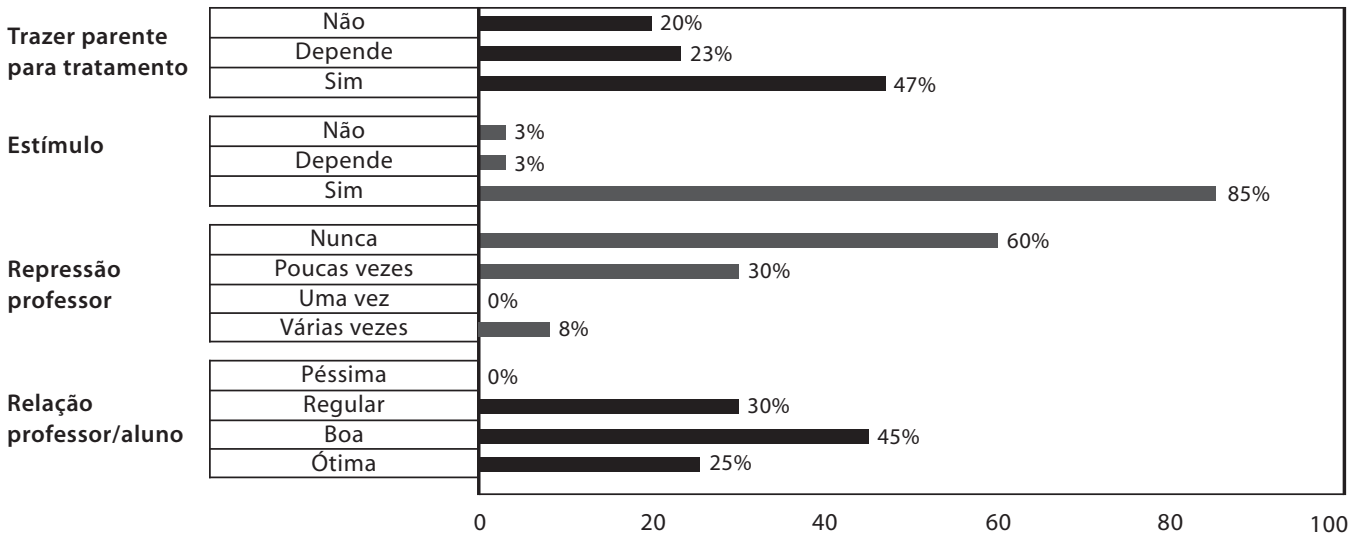

Fonte: Os autores

Nota: As variáveis que não totalizaram 100\% referem-se a perguntas não respondidas.

Os professores que perceberam uma relação professor-aluno regular destacaram falta de compreensão de limites por parte dos alunos (um professor), pressão psicológica que alguns professores exercem sobre os alunos (um professor), falta de quantitativo de professores (três professores), falta de interação professor/aluno (quatro professores) e mau exemplo de alguns professores ao falarem mal dos colegas na frente dos alunos (um professor) como motivos que norteiam um relacionamento pessoal inadequado. Já os alunos que avaliaram sua relação com os professores nessa mesma categoria destacaram que ela não é melhor pela falta de interação pedagógica/social (dez alunos), falta de comunicação/diálogo (dois alunos), desrespeito ao horário de aula (três alunos), sentimento de superioridade ou arrogância ou incompreensão ou autoritarismo que os professores demonstram (12 alunos), há falta de acessibilidade aos professores e atenção destes com os alunos (cinco alunos), ocorre paternalismo com determinados alunos e exclusão a outros (um aluno), há desinteresse/professores desestimulados, acomodados/indiferentes com o ensino (seis alunos), ocorrem ameaças do professor/ intimidação/pressão psicológica (quatro alunos), há variação de acordo com o professor (um aluno) e frieza/distanciamento (dois alunos).

Os alunos entrevistados que classificaram a relação como boa apontaram atenção/compreensão (13 alunos), interação pedagógica e social (três alunos), profissionalismo dos professores (um aluno), respeito mútuo (seis alunos), segurança e prestatividade dos professores (um aluno) e disponibilidade dos 
professores ao diálogo (13 alunos) como pontos positivos valorizados nesse contexto. Em contrapartida, os docentes que avaliaram a relação como boa justificaram sua resposta pela interação pedagógica e social (quatro professores), respeito mútuo (dois professores), acessibilidade e atenção (um professor), desigualdade de conhecimento (um professor), dedicação dos alunos (um professor) e quantidade satisfatória de docentes (um professor).

Conforme a Gráfico 1, nota-se que os alunos afirmaram ter sido repreendidos pelos professores na frente de um paciente poucas vezes $(34 \%)$ ou nunca o terem sido (35\%). Os alunos que afirmaram já terem sido repreendidos apontam que, quando isso ocorreu, se sentiram constrangidos/desconfortáveis (28 alunos), humilhados/ridicularizados (oito alunos), despreparados/desestimulados (quatro alunos), inferiores/péssimos (14 alunos), injustiçados (11 alunos) ou desmoralizados com o paciente (três alunos). Aceitou normalmente a crítica (um aluno), sentiu-se indiferente (um aluno) e transmitindo insegurança ao paciente (cinco alunos). De acordo com a Figura 2, a maioria dos professores (60\%) afirma nunca ter repreendido um aluno dessa forma e aqueles que consideraram ter repreendido poucas vezes $(30 \%)$ afirmaram que tiveram a sensação de dever cumprido ou que estavam minimizando danos no tratamento ao paciente (oito professores), desconfortáveis (quatro professores), constrangido (um professor) e normal (um professor). Ao questionar o aluno se este já discutiu em tom agressivo com um professor, a grande maioria (95\%) respondeu que isso nunca ocorreu e todos os professores que responderam ao questionário afirmaram também que isso nunca ocorreu.

Conforme apresentado nos Gráficos 1 e 2, a maioria dos alunos (56\%) afirmou que é estimulada pelo professor a esclarecer o procedimento a ser realizado para o paciente, e $85 \%$ dos professores afirmaram que sempre estimulam o aluno para tal. Uma parcela de $16 \%$ dos alunos e $20 \%$ dos professores afirmou que não traria um parente seu para ser tratado pelos acadêmicos de odontologia, sob orientação de um professor, e $48 \%$ dos alunos e $23 \%$ dos professores afirmaram que dependeria de alguns fatores.

Os resultados evidenciaram que os alunos norteiam sua decisão de trazer um parente para ser tratado no curso de Odontologia, mediante a análise de quem será o professor orientador (19 alunos), qual acadêmico realizará o tratamento (nove alunos), o período em que o acadêmico se encontra (um aluno), a disciplina (12 alunos), a qualidade do material disponível para tratamento (um aluno), a estrutura física do ambulatório (dois alunos), a morosidade do tratamento (um aluno), as condições de biossegurança do ambulatório (cinco alunos), a complexidade do procedimento (três alunos) e a urgência do tratamento a ser realizado (um aluno). Já os professores priorizaram a análise da complexidade do procedimento (cinco professores), o professor orientador (dois professores), o aluno (um professor) e a urgência 
do tratamento (um professor). Ao serem questionados sobre os motivos que determinavam sua decisão de trazer um parente para ser tratado no curso, os fatores apontados pelos alunos foram a confiança nos acadêmicos e nos professores (oito alunos), a qualidade do ensino (três alunos), a qualidade e bons resultados dos tratamentos (cinco alunos) e o baixo custo (um aluno). Os professores destacaram também a confiança no aluno (cinco professores) e na orientação dos professores (quatro professores), a gratuidade de alguns tratamentos, o que permite o atendimento de pacientes com baixa condição financeira (um professor) e a qualidade do serviço (um professor).

\section{Discussão}

A educação odontológica vem se notabilizando por suas iniciativas de mudanças na última década. O modelo flexneriano adotado pelas IES na área da saúde, centrado numa lógica linear, fragmentado, com ênfase no tecnicismo e no afastamento das questões sociais se esgota, abrindo espaço para a implantação de um modelo crítico, com disciplinas que interagem entre si e que procuram integrar ensino e serviço odontológico, respaldado pelas DCNs, as quais vêm construir um novo perfil acadêmico e profissional, com competências, habilidades e conteúdos contemporâneos, condizentes com as exigências do mercado de trabalho e as demandas sociais (Morita, 2007; Araújo, 2006; Brasil, 2002).

O curso de Odontologia da Ufes passa, desde o ano de 2007, por uma mudança curricular baseada nas DCNs e foi contemplado pelo Programa Nacional de Reorientação da Formação Profissional em Saúde (Pró-Saúde), instituído pela portaria interministerial MS/MEC n. ${ }^{\circ} 2.101$, de 3 de novembro de 2005, o qual visa reorientar o processo de formação, de modo a oferecer à sociedade profissionais habilitados para responder às necessidades da população brasileira e à operacionalização do SUS, sendo portanto, um cenário de metamorfose (Brasil, 2007).

Entretanto, essas mudanças trazem consigo a necessidade de reorientação da prática docente, o que, na maioria das vezes, provoca ansiedade acrescida de insegurança e desconforto, gerando conflitos entre os atores envolvidos nesse processo de transformação. Entende-se que uma relação professor-aluno conflituosa restringe o desenvolvimento de proposições de mudanças. Já um trabalho em conjunto entre eles facilita um processo ensinoaprendizagem em consonância com as propostas do curso e ressignifica a relação de hierarquia e poder para um relacionamento de parceria e corresponsabilidade pelo processo de aprendizagem (Masetto, 2006).

Verifica-se nos resultados dessa pesquisa a valorização, por parte de alunos e professores, dos aspectos relacionais e cognitivos para [que] se 
[possa] definir uma relação boa entre eles, concordando com os resultados encontrados por Noro et al. (2006). O aspecto relacional foi representado pelas categorias relacionadas a acessibilidade, respeito e disponibilidade ao diálogo, e o aspecto cognitivo, apontado com menor frequência, pelas categorias 'segurança', 'profissionalismo', 'presença'.

A ideia de que o profissional da saúde que se tornou educador e o aluno que foi massacrado com um ensino superespecialista dicotomizado viveram um grande desafio no contexto atual de mudanças é reforçada pela opinião de Ceccim e Feuerwerker (2004). O primeiro precisa aprender a aprender, para ensinar no modelo proposto para o perfil profissional exigido, visto que a estrutura dos cursos de pós-graduação não contemplava em sua matriz disciplinas que o preparassem para a função de educador, prevalecendo, dessa forma, o desconhecimento científico do que seja o processo ensinoaprendizagem. A grande maioria dos educadores das IES se encaixa na modalidade especialista/professor, muito longe do que se espera de um educador. O segundo recebe, então, uma orientação para atender à clínica privada, saturada, longe da formação necessária para prática real da profissão.

Dessa forma, Masetto (2006) confirma a ideia ao afirmar que, no currículo tradicional, a ênfase na formação do profissional se dá no desenvolvimento de objetivos cognitivos, sendo por esse motivo estimulada a contratação de professores especialistas em sua área de conhecimento, na maioria das vezes selecionados pelo sucesso em sua atividade profissional.

Por outro lado, uma boa relação docente-discente determina um cenário propício para detecção de deficiências pedagógicas, bem como o desenvolvimento de estratégias transformadoras críticas e contextualizadas do processo ensino-aprendizagem, permitindo que o educador assuma a posição de facilitador do conhecimento. Além disso, o ensino odontológico historicamente pautou-se em fragmentação de disciplinas de grande valor técnico. Esse conhecimento especializado, na opinião de Morin (2004), impossibilita apreender o complexo. Extrai o objeto de seu contexto e de seu conjunto. Assim, a partir da proposta de mudança curricular com vistas à adequação da formação profissional às demandas dos serviços de saúde, esse ensino fragmentado e especializado deve dar lugar a uma interação disciplinar, quiçá a interdisciplinaridade.

Como revelado pelos dados, as dificuldades na relação pessoal entre professores e alunos, também como decorrência do desestímulo do professor, que se sente acomodado, também podem estar reproduzidas no serviço. Nesse sentido, as relações instituídas entre professores e alunos servem de guia para as relações que se formarão no futuro entre esses cirurgiões-dentistas e seus colegas de trabalho, da área da saúde ou não, concordando com Barros e Barros (2007), quando concluem que a formação não deve se restringir a uma repetição atemporal, fora das condições concretas de trabalho. 
O autoritarismo por parte dos professores, o distanciamento e a falta de diálogo, citados pelos entrevistados, que definiram a relação aluno-professor como regular, preocupam por demonstrar que de alguma forma a manutenção no modelo hierárquico de ensino odontológico esteja ocorrendo. A consequência disso pode ser a dificuldade de esses futuros profissionais trabalharem em equipe, guiados por comunicação e consenso, como observaram Esposti (2007), Esposti e Emmerich (2009) e Peduzzi (1998).

Para tanto, os docentes de odontologia, responsáveis pela transmissão do conhecimento na área, têm de se adequar, estimulando uma prática descentrada da figura do cirurgião-dentista, com privilégio à comunicação. Cirurgiões-dentistas capazes de interagir comunicativamente com outros sujeitos estarão mais adaptados a cenários que necessitem de decisão médica compartilhada, por exemplo. Já na universidade isso pode ser estimulado na relação professor-aluno-paciente. A atuação do professor como detentor da verdade e em nível superior, na relação de poder, deve dar lugar a uma participação ativa dos alunos no processo de ensino-aprendizagem.

Noro e Noro (2002) afirmam que o educador, ao respeitar a dignidade do aluno e tratá-lo com compreensão e ajuda construtiva, desenvolve a capacidade de este procurar em si mesmo as respostas para seus problemas, tornando-o responsável e agente de seu próprio processo de aprendizagem. Sobre esse aspecto, essa pesquisa mostrou que muitas vezes os alunos se sentem coagidos por correções efetuadas pelos professores, muito mais do que estes se sentem como coercivos. Essa discrepância na frequência das opiniões de docentes e discentes pode estar relacionada às diferentes visões de mundo que esses atores trazem consigo em relação à postura pedagógica e disciplinar ideal.

Este estudo demonstrou que os professores encaram como pertinente chamar a atenção dos alunos na frente dos pacientes, segundo eles, com o intuito de minimizar problemas, demonstrando uma incoerência em relação ao reflexo dessa repressão 'exagerada' na autoestima e aprendizagem do aluno, o que contraria os preceitos de educação humanizada preconizados por Rozendo et al. (1999).

Os resultados apresentados demonstraram que quase todos os entrevistados afirmaram nunca ter havido uma discussão agressiva entre professores e acadêmicos, e a grande maioria deles afirma que estimula ou é estimulada a esclarecer os procedimentos realizados ao paciente, o que demonstra uma relação de respeito à autonomia e atenção ao indivíduo, defendida também por Nuto et al. (2006) que preconizam que um bom dentista não é somente aquele com notável habilidade motora, mas, sobretudo, o que é capaz de desenvolver o respeito e responder às ansiedades do paciente. 
Foi analisada a questão da confiança no tratamento odontológico prestado na faculdade, ao se questionar alunos e professores se estes trariam um parente para ser tratado no curso. Foi observada uma frequência maior de professores que confiam em trazer parentes para tratamento na faculdade, quando comparados aos alunos, prevalecendo a análise de questões como a complexidade do procedimento e a urgência do tratamento para respaldar sua decisão, demonstrando confiança nos alunos e na orientação dos professores. Já os alunos salientaram questões de biossegurança, estrutura física dos ambulatórios e qualidade dos materiais utilizados que não foram consideradas pelos professores, demonstrando certo grau de desconhecimento deles com relação às condições estruturais.

Neste estudo, porém, a possibilidade de tratamento de pessoas de relação pessoal dos alunos e professores esteve muito relacionada à confiança $\mathrm{e}$ menos a aspectos como abuso de autoridade. Os resultados vão de encontro às conclusões que Gonçalves e Verdi (2007) chegaram, de que há problemas éticos no atendimento a pacientes nas clínicas odontológicas de ensino, com acesso privilegiado a pacientes conhecidos de professores e funcionários, num total abuso de autoridade.

Entende-se que na reconstrução do modelo de formação do cirurgiãodentista há a responsabilização de todas as partes envolvidas nesse processo. As faculdades têm introduzido conteúdos humanísticos em seu currículo, para se adaptarem às recentes necessidades, corrigir a negligência do passado em relação ao domínio afetivo da educação e cultivar a preocupação ética, o comprometimento, a humildade e simplicidade de atitudes. Em relação à questão discente, Madeira salienta que:

A resistência do educando à assimilação desse aspecto afetivo de sua formação será resolvida com meios que induzem à motivação consciente (intrínseca) e com um trabalho de totalidade dos professores. Ou melhor, de bons professores, já que essa concepção exclui professores medíocres (Madeira, 2006, p. 102).

Acerca dos docentes, instiga-se a formação de profissionais professores, trabalhando o desenvolvimento no aspecto afetivo-emocional (atenção, respeito, solidariedade) e em atitudes e valores (ética, democracia, cidadania). É possível tomar decisões sobre as ações docentes em equipe, deixando-se conhecer profissionalmente. Alterar formas pensadas exige flexibilidade, saber ouvir, ponderar, decidir (Pimenta; Anastasiou, 2005). Esse é o desafio que se coloca aos professores das IES em saúde, também em relação ao ensino da odontologia. Desafio que pode ser alcançado desde que haja abertura ao diálogo, compromisso e responsabilidade com o ensino. 


\section{Conclusão}

Os dados obtidos neste estudo permitiram concluir que para a maioria dos professores e alunos a relação entre eles é boa, há estímulo da parte dos professores para o esclarecimento dos procedimentos executados ao paciente e há confiança no tratamento clínico realizado pelo aluno. No entanto, alguns fatores podem influenciar negativamente na qualidade do processo ensinoaprendizagem, tais como: a falta de acessibilidade e de interação pedagógica e social entre os atores; a arrogância e a intimidação por parte de professores; e a falta de compreensão de limites por parte dos alunos. Entende-se que uma relação docente-discente de qualidade, isto é, pautada no respeito mútuo, no estímulo à comunicação entre docentes, alunos e pacientes e na ausência de atitudes coercitivas dos professores, pode representar um maior aproveitamento do aluno e a incorporação de valores essenciais para o exercício de uma odontologia humanizada. Além disso, servirá de exemplo para as futuras relações interprofissionais e valorização do outro, no ambiente de trabalho.

Partindo do pressuposto de que o curso estudado passa por uma mudança curricular baseada nas DCNs, considera-se imprescindível a revisão da formação didática dos docentes, para que estes estejam preparados para implementar as mudanças requeridas, de forma a valorizar o papel do aluno na construção do conhecimento, tornando-o capaz de exercer sua função social como cirurgião-dentista no futuro.

O presente estudo apresentou caráter exploratório e por isso permitiu o conhecimento parcial de uma realidade que é complexa e dinâmica. A qualidade da relação professor-aluno é um aspecto essencial para um processo ensino-aprendizagem bem-sucedido e permite o desenvolvimento de estratégias transformadoras e críticas do ensino. Portanto, pesquisas futuras que utilizem a triangulação de métodos quantitativos e qualitativos devem aprofundar o conhecimento dos aspectos subjetivos dessa relação e seus desdobramentos para o incremento do processo ensino-aprendizagem. 


\section{Notas}

1 Cirurgiã-dentista. Mestranda em Saúde Coletiva pela Universidade Federal do Espírito Santo (Ufes), Vitória, Brasil. < alineguica@hotmail.com>

Correspondência: Rua Antenor Braga, 87, Praia das Gaivotas, Vila Velha, Espírito Santo, Brasil, CEP 29102-574.

2 Cirurgiã-dentista. Mestre em Saúde Coletiva pela Universidade Federal do Espírito Santo, Vitória, Brasil. <carolina.esposti@terra.com.br>

3 Cirurgião-dentista. Doutorando em Epidemiologia em Saúde Pública pela Universidade Federal do Espírito Santo, Vitória, Brasil. <edsontheodoro@uol.com.br>

4 Professora associada do curso de graduação em Odontologia e professora do Programa de Pós-graduação em Clínicas Odontológicas da Universidade Federal do Espírito Santo, Vitória, Brasil. <majogomezlou@yahoo.com.br>

\section{Referências}

ARAÚJO, Maria Ercília. Palavras e silêncios na educação superior em odontologia. Ciência \& Saúde Coletiva, Rio de Janeiro, v. 11, n. 1, 2006. p. 179-182.

BARROS, Maria Elizabeth B.; BARROS, Regina B. A potência formativa do trabalho em equipe no campo da saúde. In: PINHEIRO, Roseni; MATTOS, Ruben A.; BARROS, Maria Elizabeth B. (Org.) Trabalho em equipe sob o eixo da integralidade: valores, saberes e práticas. Rio de Janeiro: IMS/Uerj; Cepesc; Abrasco, 2007. p. 75-84.

BORDENAVE, Juan D.; PEREIRA, Adair M. Estratégias de ensino-aprendizagem. 24 ed. Petrópolis: Vozes, 2002.

BOTAZZO, Carlos. Da arte dentária. São Paulo: Hucitec, Fapesp, 2006.

BRASIL. Ministério da Educação. Diretrizes Nacionais do curso de graduação em odontologia. Resolução CNE/CES 3, de 19 de fevereiro de 2002. Diário Oficial da União. 4 mar. 2002, seção 1, p.10.

Ministério da Saúde. Conselho Nacional de Saúde. Diretrizes e normas regulamentadoras de pesquisas envolvendo seres humanos. Informe epidemiológico do SUS, v. 5 , n. 2, 1996.

Ministério da Saúde. Programa nacional de reorientação da formação profissional em saúde-pró-saúde: objetivos, implementação e desenvolvimento potencial, Brasília, 2007.

CECCIM, Ricardo B., FEUERWERKER, Laura. Mudança na graduação das profissões de saúde sob o eixo da integralidade. Cadernos de Saúde Pública, Rio de Janeiro, v. 20, n. 5, 2004. p. 1.400-1.410.

ESPOSTI, Carolina D. D. A saúde bucal na saúde da família: ação comunicativa de Habermas guiando as relações. 2007. 141f. 
Dissertação (Mestrado em Saúde Coletiva) Programa de Pós-Graduação em Saúde Coletiva, Universidade Federal do Espírito Santo.

ESPOSTI, Carolina D. D; EMMERICH, Adauto. O cirurgião-dentista e a ação comunicativa na mediação do trabalho em equipe da Estratégia de Saúde da Família. Ciência \& Saúde Coletiva [periódico na internet] 2009. [Citado em 29 de abril de 2010]; [cerca de 15 p.]. Disponível em: <www.abrasco.org.br/ cienciaesaudecoletiva/artigos/artigo_int.php? id_artigo $=4160>$. Acesso em: 7 maio 2010 .

GONÇALVES, Evelise Ribeiro; VERDI, Marta I. Machado. Os problemas éticos no atendimento a pacientes na clínica odontológica de ensino. Ciência \& Saúde Coletiva, Rio de Janeiro, v. 12, n. 3, 2007. p.755-764.

KOVALESKI, Douglas F.; FREITAS, Sérgio F.T.; BOTAZZO, Carlos. Disciplinarização da boca, a autonomia do indivíduo na sociedade do trabalho. Ciência \& Saúde Coletiva, Rio de Janeiro, v. 11, n. 1, 2006. p. 97-103.

LAZZARIN, Helen C.; NAKAMA, Luiza; CORDONI JÚNIOR, L. O papel do professor na percepção dos alunos de odontologia. Saúde e Sociedade, São Paulo, v. 16, n. 1, 2007. p. 90-101.

MADEIRA, Miguel Carlos. Ensino, Pesquisa, Extensão. In: CARVALHO, Antônio César Perri; KRIGER, Léo. Educação odontológica. São Paulo: Artes Médicas, 2006. p. 97-103.

MASETTO, Marcos Tarciso. Um paradigma interdisciplinar para a formação do cirurgiãodentista. In: CARVALHO, Antônio César Perri; KRIGER, Léo. Educação odontológica. São Paulo: Artes Médicas, 2006. p. 31-50.
MORIN, Edgar. Os sete saberes necessários à educação do futuro. 9. ed. São Paulo: Cortez; Brasília, DF: Unesco, 2004.

MORITA, Maria. Celeste. et al. Implantação das diretrizes curriculares nacionais em odontologia. Maringá: Dental Press Editora, 2007.

NORO, Elis Maria Souza, NORO, Luiz Roberto Augusto. A autoestima como facilitador do processo ensino-aprendizagem. Revista de Humanidades, v. 17, 2002. p. 113-9.

NORO, Luiz Roberto Augusto; ALBUQUERQUE, Danielle Frota; FERREIRA, Maria Elisa Machado. O desenvolvimento do processo ensino-aprendizagem: visão do aluno e do professor. Revista da Abeno, Brasília, v. n. 2, p. 109-14, 2006.

NUTO, Sharmênia Araújo Soares et al. O processo ensino-aprendizagem e suas consequências na relação professor-aluno-paciente. Ciência \& Saúde Coletiva, Rio de Janeiro, v. 11, n. 1, 2006. p. 89-96.

PEDUZZI, Marina. Equipe multiprofissional de saúde: a interface entre o trabalho e interação. 1998. 268f. Tese (Doutorado em Saúde Coletiva) - Programa de Pós-Graduação em Saúde Coletiva, Universidade Estadual de Campinas.

PIMENTA, Selma G.; ANASTASIOU, Léa Graças. Camargo. Docência no ensino superior. 2. ed. São Paulo: Cortez, 2005.

ROZENDO, Célia Alves et al. Uma análise das práticas docentes de professores universitários da área de saúde. Revista Latinoamericana de Enfermagem, Ribeirão Preto, v. 7, n. 2, 1999. p. 15-23.

Recebido em 30/03/2009

Aprovado em 28/05/2010 